\title{
New Advances in Acute Ischemic Stroke Management: Review Article
}

\author{
Hossein Aghamiri ${ }^{1}$, Sepideh Paybast ${ }^{2 *}$, Behnam Safarpour Lima ${ }^{1 \oplus}$, Behnam Mansoori $^{{ }^{1}}$ \\ 'Imam Hossein Hospital, Shahid Beheshti University of Medical Sciences and Health, Tehran, Iran \\ ${ }^{2}$ Neurology Department, Bou Ali Sina Hospital, Qazvin University of Medical Sciences and Health, Qazvin, Iran
}

\begin{abstract}
Cerebrovascular disease is the second cause of death and the sixth cause of morbidity worldwide which will rise to fourth place by 2020. The treatment strategies for acute ischemic stroke (AIS) divided into two groups, including intravenous or intra-arterial thrombolysis and mechanical thrombectomy. Regarding growing development in the realm of diagnosis and treatment of stroke through state-of-the-art approaches, including emergent thrombectomy, there are new opportunities for investigation in this area. This is while a rough rate of $85 \%$ for strokes is occupied by, and the remained is hemorrhagic. Hence, the present study aimed to review recent advances in AIS with a focus on emergent thrombectomy. Here, we first provided the relevant history, and then the recent advances were discussed. The library data collection method was employed so that such databases as Web of Science, PubMed, and Science Direct used for data extraction. The evidence confirms the importance of emergent thrombectomy as all believe the famous statement "time is the brain." However, further investigations are required to find more strong evidence accordingly.

Keywords: Ischemic stroke; Thrombectomy; Thrombolysis.
\end{abstract}

\author{
*Correspondence to \\ Sepideh Paybast, Assistant \\ Professor, Department of \\ Neurology, Bou Ali Sina \\ Hospital, Qazvin University of \\ Medical Science and Health, \\ Qazvin, Iran. \\ Tel: +989125967487; \\ Fax: +9828341386165 \\ Email: \\ sepideh.paybast@yahoo.com \\ s.paybast@qums.ac.i
}

Published online March 10 2020

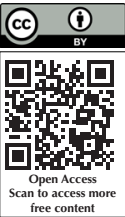

Citation: Aghamiri H, Paybast S, Safarpour Lima B, Mansoori B. New Advances in Acute Ischemic Stroke Management: Review Article. Int Clin Neurosci J. 2020;7(2):55-60. doi:10.34172/icnj.2020.02

\section{Background}

The stroke is known as an acute risk of cerebral perfusion or an unexpected beginning of a neurological deficit, which resulted from acute focal damage on the core nervous system for vascular reasons. ${ }^{1,2}$ Besides, the stroke has been one of the common causes for adult disability with an annual rate of approximately 17 million patients, making stroke as the second prominent reason for death followed by coronary artery disease. ${ }^{3}$ Also, it imposes considerable economic adverse effects on the governments and families to provide health care services, medications, and rehabilitation, forcing a productivity loss of about $\$ 33$ per year. ${ }^{4}$ The stoke is forecasted to cause $6.2 \%$ of expenses for medications, particularly in developed nations. By 2020 in developed countries, it has predicted that stroke will be accountable for $6.2 \%$ of the total burden of illness. Surprisingly, nearly $85 \%$ of risen strokes have ischemic causes, and just $15 \%$ of such issues are accompanied by or produced by hemorrhage. ${ }^{6}$ Therefore, given the provided statistics and undeniable importance of ischemic stroke, early recognition and consequently appropriate treatment is in paramount of importance for prevention and minimization of morbidity and mortality.
To this end, considering the causes of the ischemic stroke will be worthy of note. One of the prominent factors is known to be hypertension. Among youth, cardiac disease, coagulopathy disorders, carotid dissection, and illicit drug abuse considered as the main cause of stroke. ${ }^{7}$ The ischemic stroke will diagnose through unexpected blood circulation loss in a specific portion of the brain, which will lead to neurologic dysfunction. The ischemic stroke has a conventional type, which is called acute ischemic stroke (AIS), and resulted from a thrombotic/ embolic occlusion of a cerebral artery. ${ }^{8}$ The higher risk of AIS will see with higher age, and this is while we are encounter enhanced incidence of AIS worldwide, particularly in developing nations. ${ }^{9}$ In terms of gender, AIS is more common among females with a predilection in premenopausal period. ${ }^{10,11}$ Such an increasing global trend of AIS incidences makes sense to employ better treatment approaches and techniques and improvement of AIS patients' outcomes. ${ }^{12}$ Interestingly, there has been an association between risk factors as old age, severe neurological disability, not having a spouse, anemia, diabetes mellitus, and peripheral vascular disease and sores among patients suffering from AIS. ${ }^{13}$ 
Besides, as the statistics show AIS as a significant medical event which influences annually 795000 individuals around the world and provides catastrophic consequences for the corresponding patients, their families, and society, ${ }^{14}$ it can conclude that quick recognition of stroke signs by the emergency medicine is undoubtedly a key action. Alike, time-dependent treatments may significantly change the neurologic sequelae of AIS. Every physician working in emergency medicine wards should bear the well-known statement "time is brain" in his mind while assessing and treating a patient with probable AIS. ${ }^{15}$

The pathophysiology for AIS has some simplicities and complexities. The reason for simplicities is that the first incidence will be the obstruction of an intra or extracranial vessel, impairing brain parenchyma blood supply leading to infarction. The occlusion may be arisen from an artery to artery embolism, which considerably originating from an internal carotid artery (ICA) plaque, or secondary to embolization of a clot from other sides as the heart is in paramount of importance which is usually as a result of occult or overt atrial fibrillation. On the other hand, the complexity observed; lots of diverse cellular outputs happen when there is a considerable low cerebral blood flow (CBF), leading to a cascade of ischemia in brain cellular parenchyma. ${ }^{16}$ The outcomes resulted from brain ischemia are different in their color, and subsequently, the difference in the temporal evolution of ischemic cascade regarding their neuroprotection elements is possible. ${ }^{17}$ It can note that the mechanisms of ischemic injury are different in brain regions with little or no residual CBF than in areas having higher modest decreases. Also, the irreversibility of ischemic damage defers based on the presence of minimal preserved CBF in the areas which are named ischemic penumbra. ${ }^{18}$ Such a potentially salvageable area is the foundation for the treatment of AIS in the initial time of the ictus. ${ }^{19}$ In contrast, the ischemic core refers to an ischemic area that has already progressed to irreversibility. The two mentioned areas can approximate by advanced computed tomography (CT) as well as magnetic resonance imaging (MRI). ${ }^{20}$ As the ischemic damage progresses, the ischemic penumbra will shrinkage expansion of the core will be prominent, leading to irreversible damage. Interestingly, the ratio ischemic penumbra to core area is variable among patients with the same location of vascular occlusion. This diversity might not relate due to the small-vessel lacunar infarct but seems to be appropriate for both larger vessel occlusions secondary to local atherosclerosis or cardiac embolism. Important factors as temperature, metabolic factors including glucose, and efficient collateral blood supply affect the evolution of the two areas. ${ }^{21}$ The emergent therapeutic interventions as the reestablishment of CBF to the ischemic area, enhancing collateral blood flow, maybe effective on the evolution of ischemic penumbra and compose a foundation for advanced AIS therapies and those which will develop. Nowadays, AIS has entered a significant era regarding the precise knowledge of basic pathophysiology of ischemic brain injury, advanced neuroimaging modalities, and the introduction of thrombolytic therapy to restore blood flow and improved non-medical care in patients suffering from AIS. ${ }^{8}$

Also, the stroke will give rise to functional disability and death, and thus it will make AIS an emergency case requiring emergent intervention. There is no doubt that thrombolytic therapy as thrombolysis and endovascular revascularization were permanently in the lower level in patients with AIS compared to similar treatments in cardiology. ${ }^{22}$

In such acute conditions, stroke management should be quickly exerted, in a way that the patients must be considered for Intravenous thrombolysis with tissue plasminogen activator (IV-tPA) within at most 4.5 hours as well as mechanical thrombectomy for a maximum duration of $6 \mathrm{~h}$. The conducted trials reveal the window to be able opening for mechanical thrombectomy at most 24 hours of large vessel occlusion in certain cases. ${ }^{23}$

\section{Methods}

As the present study is a review work, the literature provided through looking up three authentic medical databases including Web of Science, PubMed and Science Direct with a focus on diverse Medical Subject Headings $(\mathrm{MeSH})$ terms or subcategories accessible in each of the databases mentioned above, screening all relevant papers and books.

\section{Results}

History of Emergent Thrombectomy

On the eve of 2016, IV-tPA has taken into consideration as the goal therapeutic method in AIS management. Such a therapeutic strategy resulted from a trial conducted by the National Institute of Neurological Disorders and Stroke in 1995, where the patients who underwent tIV-tPA therapy over 3 hours of initial symptoms had a higher possibility of $30 \%$ for not having a disability or minimal disability compared to placebo. $^{24}$ According to the European Cooperative Acute Stroke Study III, such a therapeutic window then got longer up to 4.5 hours from symptom onset, revealing the same profits of administration of IVtPA for the duration of 3-4.5 hours. ${ }^{25}$

However, in case of significant cerebral artery occlusion as the involvement of the intracranial internal carotid artery or the first and second segment of the middle cerebral artery (M1, M2), the efficacy of IV-tPA was inefficient showing a recanalization rate of just $4 \%-30 \%{ }^{26}$ In order to make the recanalization rate more efficient, endovascular mechanical thrombectomy introduced to evacuate acute thrombosis. The initial investigations on this approach revealed opposing findings which were justified by inappropriate sample size and suboptimal 
endovascular devices, leading to a low recanalization rate. ${ }^{27-29}$

Following advances in thrombectomy devices, releasing five successful trials in acute mechanical thrombectomy for ischemic stroke due to large-vessel occlusion in anterior circulation led to a significant change in the management of stroke. ${ }^{30-34}$ After that, emergent thrombectomy has globally considered as the leading standard for handling the patients with AIS originating by a significant vessel occlusion and is now advised in all instructions to be used for a major stroke. ${ }^{24}$

Advances in AIS Treatment Emphasizing on the Emergent Thrombectomy

In comparison to the former negative thrombectomy, one of the considerable advances was the introduction of newer stent retriever devices leading to a higher rate of recanalization. In this new trend, a nearly complete recanalization (TICI $2 \mathrm{~b} / 3$ ) was realized among 59\%-88\% of patients, by analogy to intra-arterial tPA and firstgeneration devices with an achievement among 25\%-41\% of patients. ${ }^{24}$

The other thrombectomy device used in 2016 was the direct aspiration catheter (ADAPT technique) employing for removal of the thrombosis through a large-bore endovascular catheter. The multiple single-center series supported the ADAPT, demonstrating remarkable result, and even higher than previous stent retrievers. ${ }^{35}$ In addition to what mentioned above, the 2016 THERAPY trial was the only randomized investigation for comparison of aspiration thrombectomy against IV-tPA alone, terminating too soon regarding the limited sample size upon publication of the positive stent retriever trial which failed to reveal a considerable difference from aspiration thrombectomy benefits to merely intravenous thrombolysis. ${ }^{36}$

Similarly, Cerejo et $\mathrm{al}^{37}$ employed emergent mechanical thrombectomy in the management of AIS. This trial was conducted through the Mind frame Capture LP system and considered as an initial single-center experience. They aimed to offer their basic experiments with the Mind frame Capture LP device. This device designed for mechanical thrombectomy among small cerebral arteries. In the procedure, a retrospective chart review conducted of patients who underwent a Mind frame device assisted emergent thrombectomy. Their findings approved the safety and efficacy of the Mind frame device for prompt treatment of AISs comprising small-caliber intracranial vessels.

Anadani et $\mathrm{al}^{38}$ argue that emergent carotid artery stenting along with mechanical thrombectomy, can be an effective treatment for the patients with AIS as a consequence of thrombosis in the anterior circulation. To this end, they studied the safety of emergent carotid artery stenting-mechanical thrombectomy method among society with a stroke under prior IV-tPA. Their results confirmed no association between emergent carotid artery stenting-mechanical thrombectomy and a higher risk of hemorrhagic transformation among patients receiving IV-tPA before the intervention.

Besides, a revolution in interventional therapeutic approaches in AIS realized applying stent-like thrombectomy devices named stent retrievers. ${ }^{39}$ Due to being quite retrievable, such devices provide the profits of both quick flow restoration and mechanical thrombectomy, and thus, great recanalization outcomes will realize with a rate of $90 \%$. The similar investigations report desirable clinical findings for three months. ${ }^{40}$ Such an improvement can attribute to quick and efficient clot removal and the likelihood of temporary restoration flow. ${ }^{41}$ Additionally, the application of stent retriever devices will be relevant to low symptomatic ICH and mortality rates. The latter shows the low rate of symptomatic $\mathrm{ICH}$, as well as safe flow-restoration, means by an analogy to the older thrombectomy. ${ }^{42}$ In this approach, the target vessel entered with a 0.014 -inch guidewire and a proper microcatheter with a size of 0.018-0.027 inches. The thrombus has crossed with the guidewire, and the microcatheter has distally located to the thrombus. The stent retriever is advanced to the distal end of the microcatheter. In the following, the microcatheter has got away to expand the stent retriever under fluoroscopy. A control angiogram conducted followed-by the prosperous unfolding of the device. The sizes of such devices vary $3.0 \times 15-6.0 \times 30 \mathrm{~mm}$; nonetheless, commonly, a $6.0-\mathrm{mm}$ device is employed. Upon a short while, the stent retriever receded with continuous aspiration. The scheme will iterate as long as a TICI grade of $2 \mathrm{~b}$ or three is reached. ${ }^{43}$

For instance, among plenty of conducted relevant trials, like the first, we can refer to the study carried out in 2014 entitled "Multicenter Randomized Clinical Trial of Endovascular Treatment for Acute Ischemic Stroke in the Netherlands" or MR CLEAN. ${ }^{29}$ Where 500 patients with AIS due to a large vessel occlusion in anterior circulation confirmed with CTA presenting within 6 hours from ictus were included in the study to receive either endovascular therapy or ordinary medical care. $81.5 \%$ of patients were under endovascular intervention, of which $90.6 \%$ received rTPA before endovascular treatment. The 90 day prognosis of the patients was statistically different between two groups, as $13.5 \%$ points (adjusted odds ratio 1.67) of mRs observed in the endovascular group. In a similar pattern, a provisional analysis of the rest 4 EVT trials: ESCAPE, ${ }^{32}$ REVASCAT, ${ }^{31}$ EXTEND-IA trial (Extending the Time for Thrombolysis in Emergency Neurological Deficits-Intra-Arterial), ${ }^{33}$ and SWIFTPRIME $^{34}$ revealed promising results. Exclusively, the ESCAPE and EXTEND-IA trials enrolled patients with a documented favorable penumbra region. The criterion for the existence of salvageable penumbra was assumed based 
on adequate collateral circulation evident by multimodal in the ESCAPE trial and by the Rapid Processing of Perfusion and Diffusion software the EXTEND-IA group. In general, the median onset of endovascular procedure varied between 200-260 minutes, with a successful revascularization rate of 59\%-88\%. Although not overall, the mortality rate was reduced by up to $50 \%$ in the EXTEND-IA and ESCAPE trials. The HERMES (Highly Effective Reperfusion evaluated in Multiple Endovascular Stroke) trials, a recently published patient-level metaanalysis including 1287 individuals from the 5 EVT landmark trials, confirmed the previous results. A 90-day disability was considerably lower in comparison to the control group (cOR 2.49, 95\% confidence interval 1.76$3.53 ; P<0.0001$ ). The number required to treat with EVT for disability improvement by at least one point on $\mathrm{mRS}$ is 2.6. The patients' characteristics have not disregarded (elderly, time from onset to randomization >300 minutes, individuals not receiving recombinant $\mathrm{tPA}$ ) and mortality, and sICH was not different between groups. ${ }^{42}$ Another two other EVT trials including (THERAPY [The Randomized, Concurrent Controlled Trial to Assess the Penumbra System's Safety and Effectiveness in the Treatment of Acute Stroke] and THRACE [Trial and CostEffectiveness Evaluation of Intra-arterial Thrombectomy in Acute Ischemic Stroke] $)^{44,45}$ presented at the European Stroke Conference in 2015 revealed similar promising results. Other trials (POSITIVE [Perfusion Imaging Selection of Ischemic Stroke Patients for Endovascular Therapy] and DAWN [Diffusion Weighted Imaging or Computerized Tomography Perfusion Assessment With Clinical Mismatch in the Triage of Wake Up and Late Presenting Strokes Undergoing Neurointervention]) have carried out aiming to expand the golden time of therapy which were promising by $\leq 12$ and 24 hours, respectively. Taking into all considerations, IV-tPA is still the first line of treatment within 4.5 hours of AIS symptoms. In case of documented LVO with a marked salvageable penumbra, emergent EVT should consider within the first 6 hours from ictus. However, it should be noted that only less than $10 \%$ of patients with AIS undergo endovascular procedures in the United States, even in well-trained stroke centers. The most important challenges in patient selection for endovascular therapy include lacunar infarct, stroke in evolution, large-vessel occlusion leading to severe ischemic infarct with a high NIHSS score, and unknown time of the onset which has mostly seen as wake-up stroke. Wake-upstrokes constitute approximately $20 \%$ of all ischemic strokes and usually hampered of acute reperfusion therapy according to uncertain timing. ${ }^{46}$ A series of DEFUSE trials (Diffusion and Perfusion Imaging Evaluation for Understanding Stroke Evolution $)^{47,48}$ introduced the application of perfusion imaging to evaluate the salvageable presence penumbra in patients referring to stroke center later than the golden time of treatment. Currently, DEFUSE-3 is under progress, including patients presented within $\leq 16$ hours of symptoms who are not a candidate for IV or IA tPA therapies.

Additionally, the reports are suggestive of better prognosis for patients who admitted in a multidisciplinary stroke unit even for those who do not receive acute reperfusion therapy compared to individuals hospitalized in general neurology centers with a similar hospitalization period. ${ }^{49}$

Similarly, Heit et $\mathrm{al}^{50}$ provided some evidence that proves the applicability of perfusion CT (PCT) imaging in preparing critical information for triage of AIS patients to EVT. Besides, they also showed that PCT could specify both ischemic penumbra and core infraction, and this is while those having any mismatch between these two mentioned areas will most probably be able to take advantage of EVT. Finally, they argue the usability of PCT in the identification and localization of large-vessel occlusions.

Despite all advantages of the stent retriever, clinical experiences have shown the positions which are resistant to recanalization efforts of that, including terminal ICA, middle cerebral artery bifurcation and trifurcation thrombosis as well as complicated thrombi configuration for which an alternative technique may be the direct aspiration of the thrombus. This approach made a prompt evolution in mechanical thrombectomy, is widely employed in plenty of clinical experiments. ${ }^{51}$ Most recently, some newer aspiration means have been applied and taken into development, such as making a new variation in the distal inner diameters of the catheter; as a result, this approach is in some centers used as a primary technique for intracranial artery occlusion. The newer investigations revealed the aspiration technique with reasonable safety and effectiveness of the EVT method with clinical results compared with the approaches used in the stent retriever devices. ${ }^{52,53}$ As the main profits made by this approach, one can point to the short process time and considerable clinical outcomes. ${ }^{52}$ In the case of utilizing this approach, the thrombus passed with the microwire and microcatheter, and the aspiration catheter directly located in the thrombus proximal part. Both microwire and microcatheter will eliminate. A lack of backflow characterizes thrombosis entrapment. The catheter has then retrieved with constant negative pressure to avoid loss of thrombus. Following retrieval of each clot fragments, the procedure will iterate as long as the achievement of a TICI grade of $\geq 2$ or $3 .{ }^{54}$

In addition to the approaches mentioned above, tandem occlusions can state, which consists of simultaneous extra and intracranial stenosis of ICA. Although this technique is not conventional, it provides challenging therapeutic conditions considering the AIS. ${ }^{42}$ The mechanism of extracranial ICA segment occlusion is different from 
other cerebrovascular processes. Here, the primary pathophysiology is ruptured atherosclerotic plaque and superimposed thrombus, which has seen in acute occlusion of the coronary arteries. Emergent stenting is, therefore, critical in this situation. ${ }^{43}$

Xiong et $\mathrm{al}^{55}$ in their investigation and review on the management of AIS showed that emergent thrombectomy is a considerably effective treatment for patients suffering from large vessel occlusion during 6-8 hours of signs outset. Also, the time window for thrombectomy recommended being 24 hours among patients with acute posterior circulation large artery occlusion.

\section{Conclusion}

Many several advances have recently provided for the treatment of AIS. The evidence suggests that endovascular thrombectomy is substantially helpful for patients with underlying large vessel occlusion in both early and late stages of the disease. However, intravenous thrombolysis can still consider as an acute treatment for plenty of patients with AIS (those not candidates for thrombectomy or those deprived of thrombectomy).

\section{Authors' Contributions}

SP developed the idea for the position paper, chaired the project, wrote the initial draft of the manuscript which was fully reviewed and revised by the other authors. it should be noted it was approved by all the authors.

\section{Conflict of Interest Disclosure}

The authors declare that they have no conflict of interests.

\section{Ethical Statement}

We testify that all the authors have been actively involved in substantive work leading to the manuscript and will hold themselves jointly and individually responsible for its content.

\section{References}

1. Salinet ASM, Minhas JS, Panerai RB, Bor-Seng-Shu E, Robinson TG. Do acute stroke patients develop hypocapnia? a systematic review and meta-analysis. J Neurol Sci. 2019;402:30-9. doi: 10.1016/j.jns.2019.04.038.

2. Sacco RL, Kasner SE, Broderick JP, Caplan LR, Connors JJ, Culebras A, et al. An updated definition of stroke for the 21st century: a statement for healthcare professionals from the American Heart Association/American Stroke Association. Stroke. 2013;44(7):2064-89. doi: 10.1161/ STR.0b013e318296aeca.

3. Lopez AD, Mathers CD, Ezzati M, Jamison DT, Murray CJ. Global and regional burden of disease and risk factors, 2001: systematic analysis of population health data. Lancet. 2006;367(9524):1747-57. doi: 10.1016/s01406736(06)68770-9.

4. French BR, Boddepalli RS, Govindarajan R. Acute ischemic stroke: current status and future directions. Mo Med. 2016;113(6):480-6.

5. Menken M, Munsat TL, Toole JF. The global burden of disease study: implications for neurology. Arch Neurol. 2000;57(3):418-20. doi: 10.1001/archneur.57.3.418.

6. Mozaffarian D, Benjamin EJ, Go AS, Arnett DK, Blaha MJ, Cushman M, et al. Heart disease and stroke statistics-2016 update: a report from the American Heart Association. Circulation. 2016;133(4):e38-360. doi: 10.1161/

\section{cir.0000000000000350}

7. Sarti C, Kaarisalo M, Tuomilehto J. The relationship between cholesterol and stroke: implications for antihyperlipidaemic therapy in older patients. Drugs Aging. 2000;17(1):33-51. doi: 10.2165/00002512-200017010-00003.

8. Catanese L, Tarsia J, Fisher M. Acute ischemic stroke therapy overview. Circ Res. 2017;120(3):541-58. doi: 10.1161/ circresaha.116.309278.

9. Feigin $\mathrm{VL}$, Forouzanfar $\mathrm{MH}$, Krishnamurthi $\mathrm{R}$, Mensah GA Connor M, Bennett DA, et al. Global and regional burden of stroke during 1990-2010: findings from the Global Burden of Disease Study 2010. Lancet. 2014;383(9913):245-54. doi: 10.1016/s0140-6736(13)61953-4.

10. Koton S, Schneider AL, Rosamond WD, Shahar E, Sang Y, Gottesman RF, et al. Stroke incidence and mortality trends in US communities, 1987 to 2011. JAMA. 2014;312(3):259-68. doi: 10.1001/jama.2014.7692.

11. Towfighi A, Saver JL, Engelhardt R, Ovbiagele B. A midlife stroke surge among women in the United States. Neurology. 2007;69(20):1898-904. doi: 10.1212/01. wnl.0000268491.89956.c2.

12. Allinson KSJ. Deaths related to stroke and cerebrovascular disease. Diagn Histopathol. 2019;25(11):444-52. doi: 10.1016/j.mpdhp.2019.07.009.

13. Liao X, Ju Y, Liu G, Zhao X, Wang Y, Wang Y. Risk factors for pressure sores in hospitalized acute ischemic stroke patients. J Stroke Cerebrovasc Dis. 2019;28(7):2026-30. doi: 10.1016/j. jstrokecerebrovasdis.2019.02.033.

14. Benjamin EJ, Virani SS, Callaway CW, Chamberlain AM, Chang AR, Cheng S, et al. Heart disease and stroke statistics-2018 update: a report from the American Heart Association. Circulation. 2018;137(12):e67-e492. doi: 10.1161/cir.0000000000000558.

15. Urdaneta $A E$, Bhalla P. Cutting edge acute ischemic stroke management. Emerg Med Clin North Am. 2019;37(3):365-79. doi: 10.1016/j.emc.2019.03.001.

16. Puyal J, Ginet V, Clarke PG. Multiple interacting cell death mechanisms in the mediation of excitotoxicity and ischemic brain damage: a challengefor neuroprotection. Prog Neurobiol. 2013;105:24-48. doi: 10.1016/j.pneurobio.2013.03.002.

17. Moskowitz MA, Lo EH, ladecola C. The science of stroke: mechanisms in search of treatments. Neuron. 2010;67(2):18198. doi: 10.1016/j.neuron.2010.07.002.

18. Bardutzky J, Shen Q, Bouley J, Sotak $\mathrm{CH}$, Duong TQ, Fisher M. Perfusion and diffusion imaging in acute focal cerebral ischemia: temporal vs. spatial resolution. Brain Res. 2005;1043(1-2):155-62. doi: 10.1016/j. brainres.2005.02.073.

19. Fisher M, Bastan B. Identifying and utilizing the ischemic penumbra. Neurology. 2012;79(13 Suppl 1):S79-85. doi: 10.1212/WNL.0b013e3182695814.

20. Fisher M, Albers GW. Advanced imaging to extend the therapeutic time window of acute ischemic stroke. Ann Neurol. 2013;73(1):4-9. doi: 10.1002/ana.23744.

21. Heiss WD. The ischemic penumbra: how does tissue injury evolve? Ann N Y Acad Sci. 2012;1268:26-34. doi: 10.1111/j.1749-6632.2012.06668.x.

22. Saver JL. Time is brain--quantified. Stroke. 2006;37(1):263-6. doi: 10.1161/01.STR.0000196957.55928.ab.

23. James PA, Oparil S, Carter BL, Cushman WC, DennisonHimmelfarb C, Handler J, et al. 2014 evidence-based guideline for the management of high blood pressure in adults: report from the panel members appointed to the Eighth Joint National Committee (JNC 8). JAMA. 2014;311(5):50720. doi: 10.1001/jama.2013.284427.

24. Tsang AC, Yeung RW, Tse MM, Lee R, Lui WM. Emergency thrombectomy for acute ischaemic stroke: current evidence, international guidelines, and local clinical practice. Hong 
Kong Med J. 2018;24(1):73-80. doi: 10.12809/hkmj176296.

25. Hacke W, Kaste M, Bluhmki E, Brozman M, Dávalos A, Guidetti D, et al. Thrombolysis with alteplase 3 to 4.5 hours after acute ischemic stroke. N Engl J Med. 2008;359(13):131729. doi: 10.1056/NEJMoa0804656.

26. Bhatia R, Hill MD, Shobha N, Menon B, Bal S, Kochar P, et al. Low rates of acute recanalization with intravenous recombinant tissue plasminogen activator in ischemic stroke: real-world experience and a call for action. Stroke. 2010;41(10):2254-8. doi: 10.1161/strokeaha.110.592535.

27. Broderick JP, Palesch YY, Demchuk AM, Yeatts SD, Khatri P, Hill MD, et al. Endovascular therapy after intravenous t-PA versus t-PA alone for stroke. N Engl J Med. 2013;368(10):893903. doi: 10.1056/NEJMoa1214300.

28. Ciccone A, Valvassori L, Nichelatti M, Sgoifo A, Ponzio M, Sterzi $R$, et al. Endovascular treatment for acute ischemic stroke. N Engl J Med. 2013;368(10):904-13. doi: 10.1056/ NEJMoa1213701.

29. Kidwell CS, Jahan R, Gornbein J, Alger JR, Nenov V, Ajani Z, et al. A trial of imaging selection and endovascular treatment for ischemic stroke. N Engl J Med. 2013;368(10):914-23. doi: 10.1056/NEJMoa1212793.

30. Berkhemer OA, Fransen PS, Beumer D, van den Berg LA, Lingsma HF, Yoo AJ, et al. A randomized trial of intraarterial treatment for acute ischemic stroke. N Engl J Med. 2015;372(1):11-20. doi: 10.1056/NEJMoa1411587.

31. Jovin TG, Chamorro A, Cobo E, de Miquel MA, Molina CA, Rovira A, et al. Thrombectomy within 8 hours after symptom onset in ischemic stroke. N Engl J Med. 2015;372(24):2296306. doi: 10.1056/NEJMoa1503780.

32. Goyal M, Demchuk AM, Menon BK, Eesa M, Rempel JL, Thornton J, et al. Randomized assessment of rapid endovascular treatment of ischemic stroke. N Engl J Med. 2015;372(11):1019-30. doi: 10.1056/NEJMoa1414905.

33. Campbell BCV, Donnan GA, Lees KR, Hacke W, Khatri P, Hill MD, et al. Endovascular stent thrombectomy: the new standard of care for large vessel ischaemic stroke. Lancet Neurol. 2015;14(8):846-54. doi: 10.1016/s1474-4422(15)00140-4.

34. Saver JL, Goyal M, Bonafe A, Diener HC, Levy El, Pereira VM, et al. Stent-retriever thrombectomy after intravenous t-PA vs. t-PA alone in stroke. N Engl J Med. 2015;372(24):2285-95. doi: 10.1056/NEJMoa1415061.

35. Hentschel KA, Daou B, Chalouhi N, Starke RM, Clark S, Gandhe $A$, et al. Comparison of non-stent retriever and stent retriever mechanical thrombectomy devices for the endovascular treatment of acute ischemic stroke. J Neurosurg. 2017;126(4):1123-30. doi: 10.3171/2016.2.jns152086.

36. Mocco J, Zaidat OO, von Kummer R, Yoo AJ, Gupta R, Lopes $D$, et al. Aspiration thrombectomy after intravenous alteplase versus intravenous alteplase alone. Stroke. 2016;47(9):23318. doi: 10.1161/strokeaha.116.013372.

37. Cerejo R, John S, Bauer A, Hussain MS, Bain M, Rasmussen $\mathrm{P}$, et al. Emergent mechanical thrombectomy for acute stroke using the Mindframe Capture LP system: initial single-center experience. J Neurointerv Surg. 2016;8(11):1178-80. doi: 10.1136/neurintsurg-2015-012078.

38. Anadani M, Spiotta AM, Alawieh A, Turjman F, Piotin $M$, Haussen DC, et al. Emergent carotid stenting plus thrombectomy after thrombolysis in tandem strokes: analysis of the TITAN registry. Stroke. 2019;50(8):2250-2. doi: 10.1161/strokeaha.118.024733.

39. Roth C, Papanagiotou P, Behnke S, Walter S, Haass A, Becker $C$, et al. Stent-assisted mechanical recanalization for treatment of acute intracerebral artery occlusions. Stroke. 2010;41(11):2559-67. doi: 10.1161/strokeaha.110.592071.

40. Kastrup A, Brunner F, Wasser K, Hildebrandt H, Roth
C, Winterhalter $M$, et al. Endovascular therapy versus thrombolysis in patients with anterior circulation stroke in everyday clinical practice. Int J Stroke. 2016;11(5):544-8. doi: 10.1177/1747493016641948.

41. Papanagiotou P, Roth C, Walter S, Behnke S, Politi M, Fassbender $\mathrm{K}$, et al. Treatment of acute cerebral artery occlusion with a fully recoverable intracranial stent: a new technique. Circulation. 2010;121(23):2605-6. doi: 10.1161/ circulationaha.110.948166.

42. Goyal M, Menon BK, van Zwam WH, Dippel DW, Mitchell PJ, Demchuk AM, et al. Endovascular thrombectomy after large-vessel ischaemic stroke: a meta-analysis of individual patient data from five randomised trials. Lancet. 2016;387(10029):1723-31. doi: 10.1016/s01406736(16)00163-x.

43. Papanagiotou P, White CJ. Endovascular Reperfusion Strategies for Acute Stroke. JACC Cardiovasc Interv. 2016;9(4):307-17. doi: 10.1016/j.jcin.2015.11.014.

44. Bracard S, Guillemin F, Ducrocq X. Abstract 7: Thrace Study: Final Results. Stroke. 2016;47(Suppl 1):A7. doi: doi:10.1161/ str.47.suppl_1.7.

45. Mocco J, Zaidat OO, von Kummer R, Yoo AJ, Gupta R, Lopes $D$, et al. Results of the therapy trial: A prospective, randomized trial to define the role of mechanical thrombectomy as adjunctive treatment to IV rtPA in acute ischemic stroke. Int J Stroke. 2015;10(Suppl 2):10.

46. Thomalla G, Gerloff C. Treatment concepts for wake-up stroke and stroke with unknown time of symptom onset. Stroke. 2015;46(9):2707-13. doi: 10.1161/strokeaha.115.009701.

47. Lansberg MG, Straka M, Kemp S, Mlynash M, Wechsler LR, Jovin TG, et al. MRI profile and response to endovascular reperfusion after stroke (DEFUSE 2): a prospective cohort study. Lancet Neurol. 2012;11(10):860-7. doi: 10.1016/ s1474-4422(12)70203-x.

48. Albers GW, Thijs VN, Wechsler L, Kemp S, Schlaug G, Skalabrin E, et al. Magnetic resonance imaging profiles predict clinical response to early reperfusion: the diffusion and perfusion imaging evaluation for understanding stroke evolution (DEFUSE) study. Ann Neurol. 2006;60(5):508-17. doi: 10.1002/ana.20976.

49. Organised inpatient (stroke unit) care for stroke. Cochrane Database Syst Rev. 2013(9):CD000197. doi: 10.1002/14651858.CD000197.pub3.

50. Heit JJ, Sussman ES, Wintermark M. Perfusion Computed Tomography in Acute Ischemic Stroke. Radiol Clin North Am. 2019;57(6):1109-16. doi: 10.1016/j.rcl.2019.06.003.

51. Grunwald IQ, Walter S, Papanagiotou P, Krick C, Hartmann K, Dautermann A, et al. Revascularization in acute ischaemic stroke using the penumbra system: the first single center experience. Eur J Neurol. 2009;16(11):1210-6. doi: 10.1111/j.1468-1331.2009.02750.x.

52. Meyer L, Politi M, Alexandrou M, Roth C, Brunner F, Kastrup A, et al. Primary aspiration technique in endovascular stroke treatment. Hell J Radiol. 2017;2(2):20-7.

53. Lapergue B, Blanc R, Guedin P, Decroix JP, Labreuche J, Preda $C$, et al. A direct aspiration, first pass technique (ADAPT) versus stent retrievers for acute stroke therapy: an observational comparative study. AJNR Am J Neuroradiol. 2016;37(10):1860-5. doi: 10.3174/ajnr.A4840.

54. Papanagiotou P, Reith W, Kastrup A, Roth C. Current reperfusion strategies for acute stroke. Interv Cardiol Clin. 2014;3(1):145-67. doi: 10.1016/j.iccl.2013.09.008.

55. Xiong Y, Manwani B, Fisher M. Management of acute ischemic stroke. Am J Med. 2019;132(3):286-91. doi: 10.1016/j. amjmed.2018.10.019. 